\title{
Impairment of color spatial vision in chronic alcoholism measured by psychophysical methods
}

\author{
Antonio José de Oliveira Castro ${ }^{1}$, Anderson Raiol Rodrigues ${ }^{1}$, Maria Izabel Tentes Côrtes ${ }^{2}$, Luiz \\ Carlos de Lima Silveira ${ }^{1}$
}

1 Universidade Federal do Pará, Brazil

2 Universidade Federal do Amapá, Brazil

\begin{abstract}
We used psychophysical tests to evaluate spatial vision in 15 subjects with a clinical history of chronic alcoholism by measuring luminance contrast sensitivity and color discrimination. The subjects were initially subjected to clinical inquiry and ophthalmological exam. Subjects then performed psychophysical tests to measure spatial contrast thresholds using sine wave gratings of different spatial frequencies and contrasts and chromatic discrimination thresholds using the Mollon-Reffin test. For the analysis, subjects were divided into three groups according to age and compared with age-matched controls. Ten subjects had some degree of color vision loss, which was quite severe in seven cases. All subjects had normal luminance contrast sensitivity. The results suggest that color vision changes related to chronic alcoholism can occur in the absence of impairment of spatial luminance contrast sensitivity and thus is an important aspect to be considered in the clinical evaluation of this condition. Keywords: chronic alcoholism, spatial vision, color vision, dyschromatopsia, contrast sensitivity, neurotoxicology.
\end{abstract}

Received 17 December 2009; received in revised form 31 December 2009; accepted 31 December 2009. Available on line 31 December 2009.

\section{Introduction}

Chronic alcoholism is a major worldwide health problem (Glanz, Grant, Monteiro, \& Tabakoff, 2002; Marlatt \& Witkiewitz, 2002; Maillard \& Diamond, 2004; Room, Babor, \& Rehm, 2005). Epidemiological studies in the United States have shown that two-thirds of persons 14 years of age and older consume alcoholic beverages (Schorling \& Buchsbaum, 1997; Rehm \& Gmel, 2003). In Brazil, the prevalence of chronic alcohol use in the population includes approximately 9.3\% who are dependent and $15.5 \%$ who are classified as heavy users (Riley \& Marshall, 1999; Laranjeira,

Antonio José de Oliveira Castro. Instituto de Ciências da Saúde, Faculdade de Nutrição / Núcleo de Medicina Tropical, Universidade Federal do Pará, Belém, Brazil. Anderson Raiol Rodrigues, Núcleo de Medicina Tropical, Universidade Federal do Pará, Belém, Brazil. Maria Izabel Tentes Côrtes, Faculdade de Enfermagem, Universidade Federal do Amapá, Macapá, Amapá, Brazil. Luiz Carlos de Lima Silveira, Instituto de Ciências Biológicas / Núcleo de Medicina Tropical, Universidade Federal do Pará, Belém, Pará, Brazil. Correspondence regarding this article should be directed to: Antonio José de Oliveira Castro. Instituto de Ciências da Saúde, Faculdade de Nutrição, Universidade Federal do Pará, Av. Generalíssimo Deodoro, s/nº Umarizal, Belém, Pará, Brazil. E-mail: acastro@ufpa.br
Pinsky, Sanches, Zaleski, \& Caetano, 2009; World Health Organization, 2010). Problems directly related to alcohol consumption have a prevalence of 2060\% among hospitalized patients (Preedy, Reilly, Patel, Richardson, \& Peters, 1999). Alcohol consumption is estimated to cause about $20-30 \%$ of the cases of worldwide oesophageal cancer, liver cancer, liver cirrhosis, homicide, epilepsy, and motor vehicle accidents (World Health Organization, 2010). Alcohol use causes 1.8 million deaths worldwide (3.2\% of total deaths) and 58.3 million (4\% of total) DisabilityAdjusted Life Years (World Health Organization, 2010). Global alcohol consumption has increased in recent decades, with all or most of that increase occurring in developing countries, including Brazil (World Health Organization, 2009).

Ethanol is absorbed mainly in the small intestine and is detected in the blood minutes after ingestion ( $\mathrm{Li}$, Yin, Crabb, O’Connor, \& Ramchandani, 2001). Ethanol is first oxidized to acetaldehyde in the liver by alcohol dehydrogenase (Lieber, 1997), and then acetaldehyde is converted to acetate by aldehyde dehydrogenase (Lieber, 1980; Lieber, 1997; Lorimier, 2000).

Ethanol may be included in a normal diet when ingested within recommended limits (i.e., two cups of wine per day) as a source of calories (Serafini, Maiani, \& Ferro-Luzzi, 1998; Peele \& Brodsky, 2000; Lucas 
et al., 2005). Ingestion above this limit may cause physiological injury because of the effects of ethanol metabolic products such as acetaldehyde and acetate (Lieber, 1997). Therefore, excessive ethanol ingestion is a criterion used in the early diagnosis of chronic alcoholism (Preedy et al., 1999). Because of ethanol's high caloric value, excessive consumption generally causes malnutrition and vitamin deficiency (Santolaria et al., 2000; Schuckit, 2009).

After consumption, at minimum blood levels of $0.05-0.06 \%$ ethanol, several visual functions are acutely impaired, such as visual acuity (Newman \& Fletcher, 1941; Watten \& Lie, 1996), binocular fusion (Brecher, Hartman, \& Leonard, 1955), and latency time for fusion of near and distant objects (Miller, 1991). Psychophysical studies evaluating reaction time, anticipation time, and visual performance under the influence of different concentrations of ethanol in the bloodstream have shown that a person without a history of alcoholism experiences consistent impairment of psychomotor performance during the ascending limb of the blood ethanol level curve, which is more severe than during the descending limb (Wang et al., 1992). Studies of the effects of acute ethanol intoxication on contrast sensitivity to stationary and moving gratings have shown that ethanol consumption significantly affects contrast sensitivity to moving gratings but not stationary gratings, especially at high spatial frequencies (i.e., $\geq 12$ cycles per degree; Andre, Tyrrell, Leibowitz, Nicholson, \& Wang, 1994).

Chronic alcoholism is characterized by ethanol addiction. Persons with this disorder crave alcoholic beverages, develop tolerance to its intoxicating effects, and develop neurologic signs of withdrawal when they stop drinking (Diamond \& Messing, 1994; Preedy et al., 1999; Rudolf \& Priebe, 2002). The neurotoxic effects of ethanol on the nervous system include peripheral neuropathy, cerebellar degeneration, Wernicke-Korsakoff syndrome, and alcoholic nutritional amblyopia (Handler \& Perkin, 1983; Torvik \& Torp, 1986; Plant \& Perry, 1990; Ambrose, Bowden, \& Whelan, 2001; Murata et al., 2001). Alcoholic nutritional amblyopia occurs in malnourished alcoholics because of a deficiency in complex B vitamins (Zafar \& Sergott, 2008). It results from the degeneration of small retinal ganglion cells in the foveal slope, especially those that originate from the papillomacular bundle of nerve fibers connecting the nasal side of the macula to the optic nerve head (Plant \& Perry, 1990). This form of amblyopia is associated with nutritional diseases such as beriberi (thiamine deficiency) and pellagra (niacin deficiency; Merck Manual of Diagnosis and Therapy, 2008). Two factors-ethanol toxicity and malnutrition-acting independently or in association have been implicated in the pathogenesis of this disorder (Zafar \& Sergott, 2002).

Some studies have shown that subjects with a clinical history of long-term ethanol abuse have color vision impairment (Cruz-Coke \& Varela, 1965; Smith, 1972; Mergler, Blain, Lemaire, \& Lalande, 1988; Hill \& Toffolon, 1990). Cruz-Coke and Varela (1965) evaluated color vision in a group of 100 patients diagnosed with hepatic cirrhosis attributable to chronic alcoholism and found that 18 were color blind (Cruz-Coke \& Varela, 1965). Color vision impairment caused by nutritional disorders associated with chronic alcoholism has been diagnosed using Farnsworth-Munsell 28-hue or 100-hue colorarrangement tests (Hill \& Toffolon, 1990). Color vision loss occurs more often in the tritan axis than in the protan-deutan axes (Mergler et al., 1988).

The present study evaluated the color vision of patients with a history of chronic alcoholism using the Mollon-Reffin test (Mollon \& Reffin, 1989), a highly sensitive procedure that measures color vision discrimination thresholds (Regan, Reffin, \& Mollon, 1994; Rodrigues et al., 2007). This test evaluates a different aspect of human color vision compared with other color arrangement tests and provides an accurate measurement of color discrimination thresholds in an artificial context that mimics the natural environment. We also measured luminance contrast thresholds for a range of spatial frequencies using black-and-white sine wave gratings. We found an increase in color discrimination thresholds (i.e., a decrease in color discrimination ability) in a large proportion of subjects with a history of chronic alcoholism with simultaneous preservation of luminance contrast sensitivity.

\section{Method}

\section{Participants}

We studied 15 subjects (14 male, 1 female; 38 \pm 11 years old) who abused ethanol for long periods of time (16.8 \pm 7.3 years; range, 4 -27 years), with a minimum of $150 \mathrm{ml}$ of ethanol ingested per day either every day (10 subjects) or on the weekend (5 subjects). Subjects preferentially consumed distilled beverages (5 subjects), fermented beverages (4 subjects), or indiscriminately both kinds of beverages (6 subjects). The majority of subjects were members of a local Alcoholic Anonymous chapter. Subjects did not consume alcoholic beverages at the time of visual evaluation. Routine clinical and ophthalmologic examinations were performed in all subjects prior to the psychophysical measurements. The ophthalmologic examination comprised ocular refractometry, retinoscopy, visual acuity measurement, and the Ishihara pseudoisochromatic plate test. 
Exclusion criteria included a history of degenerative, toxic, traumatic, or infectious diseases that could affect the visual system.

For comparison, we tested normal control subjects without a history of alcoholism but used the same exclusion criteria as the chronic alcoholic subjects (Rodrigues et al., 2007). The controls were divided into three age groups: $16-30,31-45$, and $46-60$ years old. The number of control subjects varied between age groups. For the luminance contrast threshold norms, we measured 55 subjects in the first group (21.3 \pm 3.1 years old), 20 subjects in the second group (35.7 \pm 3.5 years old), and 19 subjects in the third group $(53.9 \pm 4.4$ years old). For the color discrimination threshold norms, we measured 50 individuals in the first group (20.8 \pm 3.0 years old $)$, 19 individuals in the second group (37.1 \pm 4.5 years old), and 10 individuals in the third group (51.7 \pm 3.6 years old; Rodrigues et al., 2007).

The study was performed according to the Ethical Norms for Research with Humans, Resolution 164/96 of the Health National Council, Brazilian Ministry of Health, and was approved by the Research Ethics Committee, Tropical Medicine Nucleus, Federal University of Pará. All subjects, both with a history of chronic alcoholism and controls, gave written informed consent to participate in the study.

\section{Hardware and software}

The software for the psychophysical tests was written using the $\mathrm{C}++$ programming language and used OFS/Motif 1.1, AIX-Windows R4, and the IBM-GL graphic library, all for the AIX 3.2.x environment. The software was developed for an IBM POWERStation RISC 6000 (IBM Corporation, New York, NY, USA). The stimuli were displayed on IBM 6091 19i color monitors, $1280 \times 1024$ pixels, $81.32 \mathrm{kHz}$ horizontal refresh rate, $77 \mathrm{~Hz}$ vertical frame rate. Stimuli were generated using IBM GT4-3D graphic adapters, 24 bit, 8 bits per gun. A procedure for gamma correction was used to obtain a linear relationship between the input voltages applied to the cathode ray tube and the output luminance levels. A dithering routine was used to obtain 10-bit gray level resolution. Luminance and chromaticity coordinates were measured with a CS-100A chroma meter (Konica Minolta, Mahwah, NJ, USA).

Software was developed based on the published literature for spatial luminance contrast threshold measurements using sine wave gratings (Westheimer, 1960; Campbell \& Green, 1965; Campbell \& Robson, 1968; Arden, 1978) and color discrimination measurements using pseudoisochromatic stimuli (Mollon \& Reffin, 1989; Regan et al., 1994). Software was developed in the "Eduardo Oswaldo Cruz" Laboratory of Neurophysiology, Biological Sciences Institute, Federal University of Pará (Belém, Pará, Brazil) by Cleidson Ronald Botelho de Souza (spatial luminance contrast sensitivity) and Anderson Raiol Rodrigues (Mollon-Reffin test for chromatic discrimination) under the advisement of Luiz Carlos de Lima Silveira and Antonio Tobias Silveira.

\section{Stimuli and procedure}

All measurements were performed monocularly, testing the right eye for right-handed subjects and the left eye for left-handed subjects. Luminance contrast sensitivity was measured at 11 spatial frequencies, ranging from 0.2 to 30 cycles/degree (Table 1; Rodrigues et al., 2007). The stimuli consisted of stationary, blackand-white (Commission Internationale de L'Éclerage [CIE] 1976 white coordinates: u' $=0.182, v^{\prime}=0.474$ ) vertical sine-wave gratings with a mean luminance of $43.5 \mathrm{~cd} / \mathrm{m}^{2}$. The stimuli were placed $3 \mathrm{~m}$ from the subject and measured $6.5^{\circ} \times 5^{\circ}$ in the visual field. Each threshold estimation was repeated six times, and the mean value represented the subject's threshold. The psychophysical procedure used for threshold determination was the method of adjustments, in which the contrast value of the grating was continuously changed by the subject until the grating was no longer visible. Contrast was defined using the Michelson equation: $C=$ (maximum luminance - [minimum luminance / maximum luminance] + minimum luminance). Contrast sensitivity was taken as the inverse of contrast threshold, and results are expressed in logarithmic units.

The Mollon-Reffin test used in the present study to measure color discrimination thresholds was a custom version of the computerized, pseudoisochromatic Cambridge Color Test. The present version was based on the published literature (Mollon \& Reffin, 1989; Regan et al., 1994) and successfully compared. The custom version was then used together with the commercially available Cambridge Color Test to provide international statistical norms for the procedure (Ventura et al., 2003) and has been used previously to study certain conditions that affect visual system performance (Silveira et al., 2003; Rodrigues et al., 2007). The subject's task consisted of discriminating a target with variable chromaticity appearing in a field of different chromaticity (i.e., reference chromaticity), which was kept constant from trial to trial. The target and field were formed by a mosaic of circular patches whose luminance varied from trial to trial and were randomly assigned to one of six equally spaced and probable levels in the range of 7.6-17 cd/ $/ \mathrm{m}^{2}$. The field diameter measured $5^{\circ}$, and the Landolt $C$ target had a $4.3^{\circ}$ outer diameter and $2.2^{\circ}$ inner diameter with a $1^{\circ}$ gap (Regan et al., 1994). Five different reference chromaticities chosen in the CIE 1976 chromaticity diagram were used 
(Regan et al., 1994): Ellipse 1 (0.215, 0.531), Ellipse 2 (0.219, 0.481), Ellipse 3 (0.225, 0.415), Ellipse 4 $(0.175,0.485)$, Ellipse $5(0.278,0.472)$. The target and field were embedded in a black background with very low luminance. Subjects were positioned $3 \mathrm{~m}$ from the screen. For each trial, the target had a chromaticity distinct from the field, and the subject had to indicate the orientation of the Landolt $\mathrm{C}$ gap: top, bottom, left, or right. The stimulus pattern was presented for $1.5 \mathrm{~s}$ and then replaced during the $3 \mathrm{~s}$ response interval by a uniform field corresponding to the black background. The chromatic contrast between target chromaticity and reference chromaticity was determined using a staircase procedure (Cornsweet, 1962). Subject nonresponses during the response interval were considered incorrect responses. The chromatic contrast thresholds were defined as the minimum vector distance between target and reference chromaticities (Regan et al., 1994). Chromatic discrimination thresholds were evaluated along 20 chromaticity axes equally spaced in the CIE
1976 chromaticity diagram. Threshold data for each reference chromaticity were then fitted with ellipses and presented in the CIE 1976 chromaticity diagram. Results from chronic alcoholics and controls were compared using the diameters of circles with an equivalent area (Rodrigues et al., 2007).

\section{Statistics}

The results obtained from control subjects were used to estimate confidence intervals and upper and lower tolerance limits (Dixon \& Massey, 1969; Salomão \& Ventura, 1995). Two-tailed tolerance intervals were calculated, encompassing $90 \%$ of the population with 95\% certainty. The results obtained from the control group for each age group (16-30, 31-45, and 46-60 years old) have been previously published (Rodrigues et al., 2007). The results obtained from chronic alcoholic subjects were individually compared with the tolerance intervals of their respective age group.

Table 1. Luminance contrast sensitivity measured with black-and-white sine wave gratings of subjects with a history of chronic alcoholism. All results were within the statistical norms of control subjects from Rodrigues et al. (2007). Contrast sensitivity was calculated as the inverse of the Michelson contrast threshold and is expressed in log units.

\begin{tabular}{|c|c|c|c|c|c|c|c|c|c|c|c|c|c|}
\hline \multirow{2}{*}{ Subject } & \multirow{2}{*}{$\begin{array}{c}\text { Age } \\
\text { (years) }\end{array}$} & \multirow{2}{*}{$\begin{array}{c}\text { Chron- } \\
\text { ic Alco- } \\
\text { holism } \\
\text { (years) }\end{array}$} & \multicolumn{11}{|c|}{ Spatial Frequency (cycles/degree) } \\
\hline & & & 0.2 & 0.5 & 0.8 & 1 & 2 & 4 & 6 & 10 & 15 & 20 & 30 \\
\hline 1 & 20 & 4 & 1.16 & 2.30 & 2.44 & 2.22 & 2.59 & 2.56 & 2.61 & 2.48 & 2.00 & 1.08 & 0.62 \\
\hline 2 & 23 & 12 & 1.10 & 1.82 & 2.02 & 2.15 & 2.24 & 2.35 & 2.35 & 2.01 & 2.11 & 1.09 & 0.63 \\
\hline 3 & 27 & 15 & 0.65 & 1.52 & 1.82 & 2.00 & 2.05 & 2.05 & 1.85 & 1.33 & 0.93 & 0.29 & 0.23 \\
\hline 4 & 29 & 14 & 1.01 & 2.00 & 2.35 & 2.30 & 2.40 & 2.61 & 2.44 & 2.29 & 0.99 & 0.39 & 0.30 \\
\hline 5 & 30 & 5 & 0.97 & 1.98 & 2.05 & 2.17 & 2.46 & 2.57 & 2.30 & 1.98 & 2.29 & 1.11 & 0.50 \\
\hline 6 & 30 & 10 & 1.03 & 1.93 & 2.09 & 2.34 & 2.39 & 2.36 & 2.29 & 2.10 & 1.91 & 1.22 & 0.49 \\
\hline 7 & 38 & 20 & 0.83 & 2.21 & 2.26 & 2.30 & 2.42 & 2.60 & 2.19 & 1.19 & 0.62 & 0.20 & 0.33 \\
\hline 8 & 38 & 28 & 0.68 & 1.25 & 1.77 & 1.81 & 2.05 & 2.12 & 1.46 & 1.41 & 0.70 & 0.37 & 0.46 \\
\hline 9 & 40 & 12 & 1.09 & 2.37 & 2.43 & 2.53 & 2.51 & 2.70 & 2.54 & 2.55 & 2.22 & 2.81 & 0.74 \\
\hline 10 & 47 & 22 & 0.75 & 1.86 & 2.19 & 2.29 & 2.46 & 2.27 & 2.24 & 1.40 & 0.98 & 0.60 & 0.36 \\
\hline 11 & 44 & 20 & 0.93 & 2.38 & 2.33 & 2.53 & 2.67 & 2.70 & 2.73 & 2.51 & 2.53 & 2.35 & 0.72 \\
\hline 12 & 49 & 22 & 0.77 & 2.14 & 2.24 & 2.28 & 2.51 & 2.40 & 2.48 & 2.35 & 1.36 & 1.17 & 0.56 \\
\hline 13 & 49 & 23 & 0.69 & 1.41 & 1.65 & 1.96 & 1.79 & 2.22 & 1.73 & 1.19 & 0.77 & 0.49 & 0.64 \\
\hline 14 & 51 & 27 & 0.80 & 2.42 & 2.66 & 2.56 & 2.73 & 2.73 & 2.56 & 2.55 & 2.44 & 1.24 & 0.63 \\
\hline $15^{*}$ & 58 & 18 & 0.90 & 2.20 & 2.48 & 2.44 & 2.61 & 2.63 & 2.30 & 2.42 & 1.41 & 0.78 & 0.26 \\
\hline
\end{tabular}

*Subject 15 was the only woman tested. 

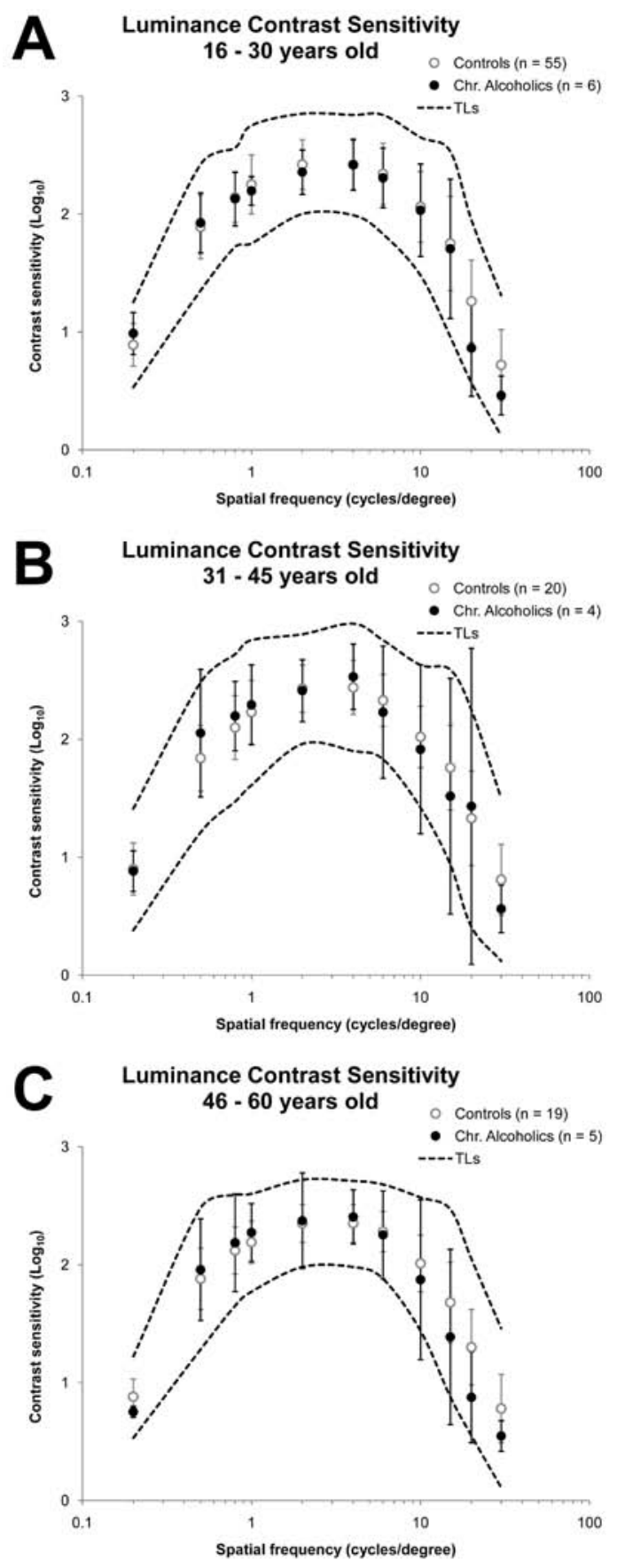

Figure 1. Luminance contrast sensitivity of chronic alcoholic subjects compared with control subjects. Means (filled circles) and standard deviations (vertical bars) for chronic alcoholic subjects are compared with means (empty circles), standard deviations (vertical bars), and upper and lower tolerance limits derived from the statistical norms of control subjects from Rodrigues et al. (2007). (A-C) Chronic alcoholic and control subjects were divided into three age groups for comparison. Contrast sensitivity was calculated as the inverse of the Michelson contrast threshold and is expressed in log units. All of the means corresponding to contrast sensitivity at different spatial frequencies for all alcoholic groups were within the tolerance limits of statistical norms of the age-matched control groups. All values for individual alcoholic subjects were also within their respective tolerance limits (Table 1). No significant differences were observed when means and standard deviations obtained from alcoholic and control subjects were compared (Student's t-test, $\mathrm{p}>$.05).
Chronic alcoholics and controls from each age group were also compared using Student's $t$-test. Additionally, chronic alcoholics and aged-matched controls were divided into two groups with an equal number of subjects per group and then compared using Student's $t$-test. The control group for this comparison was obtained by random subject selection for each age group.

\section{Results}

All subjects had normal visual acuity or decreased visual acuity that could be corrected to normal using spectacle lenses with appropriate dioptric values. All but one subject performed as normal trichromats in the Ishihara pseudoisochromatic plate test, including two of three chronic alcoholic subjects who had increased chromatic discrimination thresholds in the red-green direction of the CIE 1976 color space. The third subject (Subject \#014, male) who had this kind of change in chromatic discrimination thresholds was diagnosed as deutan red-green deficient in the Ishihara test (for details, see next section).

No subject had anatomical abnormalities that could be detected by ophthalmological examination. This was particularly important for the chronic alcoholic subjects because permanent damage to the papillomacular bundle can occur in advanced forms of alcoholism which can be detected by retinoscopy (Plant $\&$ Perry, 1990).

\section{Spatial luminance contrast sensitivity}

All 15 chronic alcoholic subjects had luminance contrast sensitivity within the tolerance limits for their age at all spatial frequencies (Table 1). All of the means corresponding to luminance contrast sensitivity at different spatial frequencies for all alcoholic groups were within the tolerance limits of the statistical norms of the age-matched control groups (Fig. 1). Additionally, no significant differences were observed when means and standard deviations obtained from the alcoholic and control groups were compared (Student's $t$-test, $p>0.05$ ).

\section{Color discrimination thresholds}

Ten of 15 chronic alcoholic subjects had some degree of color discrimination loss, which was quite severe in some of the subjects (Table 2). As a group, chronic alcoholics had higher chromatic discrimination thresholds than control subjects in all of the five locations of the color space that were investigated (Student's $t$-test, $p<$ .01; Fig. 2). In six chronic alcoholic subjects, the sizes of all five chromatic discrimination ellipses were above the upper tolerance limits of the statistical norms of control subjects (Table 2). In one additional subject, the sizes of all three ellipses were also significantly larger than the upper tolerance limits (Table 2). In the remaining three subjects, two, three, and four ellipses, respectively, were larger than the upper tolerance limits of the control subjects (Table 2). 
Table 2. Color discrimination thresholds of subjects with a history of chronic alcoholism. Thresholds were measured with the Mollon-Reffin test. The results are shown as diameters of circles with an equivalent area of the MacAdam ellipse in five different locations of the CIE 1976 chromaticity diagram. The values were calculated in u'v' CIE 1976 units and multiplied by 106. Values above the statistical norms of control subjects from Rodrigues et al. (2007) are underlined.

\begin{tabular}{cccccccc}
\hline Subject & Age (years) & $\begin{array}{c}\text { Chronic Alco- } \\
\text { holism (years) }\end{array}$ & Ellipse 1 & Ellipse 2 & Ellipse 3 & Ellipse 4 & Ellipse 5 \\
\hline 1 & 20 & 4 & $\underline{27.57}$ & $\underline{38.67}$ & $\underline{40.44}$ & $\underline{33.47}$ & $\underline{38.46}$ \\
2 & 23 & 12 & $\underline{30.12}$ & 22.26 & $\underline{30.81}$ & 22.64 & $\underline{36.44}$ \\
3 & 27 & 15 & $\underline{36.87}$ & $\underline{40.00}$ & $\underline{47.39}$ & $\underline{39.76}$ & $\underline{51.77}$ \\
$4^{*}$ & 29 & 14 & $\underline{41.64}$ & $\underline{45.91}$ & $\underline{31.66}$ & - & - \\
5 & 30 & 5 & 18.16 & 19.88 & 19.17 & 18.09 & 18.83 \\
6 & 30 & 10 & 15.61 & 16.61 & 19.30 & 21.77 & 23.00 \\
7 & 38 & 20 & $\underline{40.03}$ & $\underline{46.60}$ & $\underline{48.25}$ & $\underline{44.65}$ & $\underline{66.70}$ \\
8 & 38 & 28 & $\underline{74.15}$ & $\underline{58.53}$ & 36.17 & $\underline{46.79}$ & $\underline{54.63}$ \\
9 & 40 & 12 & $\underline{47.43}$ & $\underline{60.93}$ & $\underline{57.93}$ & $\underline{56.08}$ & $\underline{54.71}$ \\
10 & 44 & 20 & 34.35 & $\underline{34.09}$ & 36.99 & 33.28 & $\underline{42.34}$ \\
11 & 47 & 22 & 24.35 & 27.37 & 34.01 & 28.51 & 49.63 \\
12 & 49 & 22 & 40.44 & 32.49 & 33.17 & 25.64 & 44.66 \\
13 & 49 & 23 & $\underline{64.74}$ & $\underline{60.86}$ & $\underline{60.45}$ & $\underline{63.34}$ & $\underline{70.45}$ \\
14 & 51 & 27 & $\underline{60.79}$ & $\underline{66.25}$ & $\underline{100.10}$ & $\underline{69.23}$ & $\underline{112.27}$ \\
$15 * *$ & 58 & 18 & 24.62 & $\underline{26.16}$ & 24.38 & 25.17 & 35.97 \\
\hline
\end{tabular}

*Subject 4 was unavailable to be tested for Ellipses 4 and 5. **Subject 15 was the only woman tested.

For the majority of chronic alcoholic subjects, the increase in color discrimination thresholds was diffusely distributed in the color space or had some predominance along the tritan axis. For three subjects, the increase was slightly greater in the red-green direction but without similarity with typical color discrimination impairment associated with protan- or deutan-type congenital color blindness. This was also the case for one subject who had been diagnosed as deutan color deficient in the Ishihara test.

\section{Discussion}

Color vision impairment in the absence of luminance contrast sensitivity loss

The present results suggest that color vision changes related to chronic alcoholism can occur in the absence of impairment of spatial luminance contrast sensitivity, suggesting that color vision evaluation is an important aspect to be considered in the clinical examination of this condition. Additionally, the results suggest that changes in a subject's color vision may occur in the absence of pronounced anatomic changes of the eye fundus detectable by conventional retinoscopy.

At more advanced stages of chronic alcoholism, whether attributable to long-term exposure to ethanol or large quantities of daily ethanol intake, or because of the association between alcoholism and severe forms of malnutrition and vitamin deficiency, color vision dysfunction appears to be associated with decreased visual acuity, contrast sensitivity losses, visual field central defects, and anatomical signs of retinal damage, such as degeneration of the papillomacular nerve fiber bundle and atrophy of the temporal optic disk (Plant \& Perry, 1990; Sadun et al., 1994; de Lima, Carvalho, Campos, Dantas, 2006). Such deleterious effect are possible if retinal ganglion cell loss related to chronic alcoholism (see below) progresses from preferential damage to $\mathrm{P}$ and $\mathrm{K}$ ganglion cells involved with color vision in the first stages of the disease to include the several ganglion cell classes involved in achromatic vision in later stages (Silveira et al., 2004; Silveira et al., 2008). 

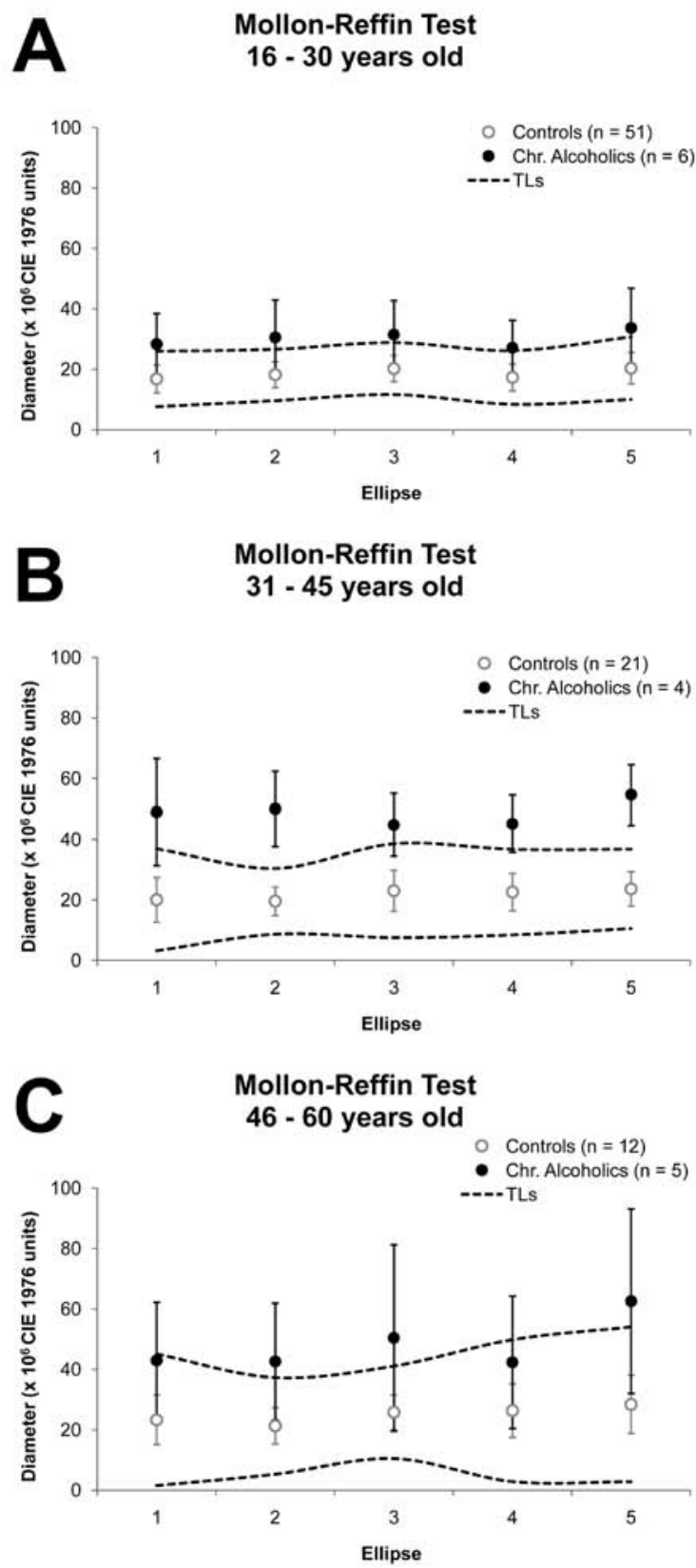

Figure 2. Color discrimination thresholds of chronic alcoholic subjects compared with control subjects. Means (filled circles) and standard deviations (vertical bars) for chronic alcoholic subjects were compared with means (empty circles), standard deviations (vertical bars), and upper and lower tolerance limits derived from the statistical norms of control subjects from Rodrigues et al. (2007). (A-C) Chronic alcoholic and control subjects were divided into three age groups for comparison. Thresholds were measured with the Mollon-Reffin test. The results are shown as diameters of circles with equivalent areas of the MacAdam ellipses in five different locations of the CIE 1976 chromaticity diagram (MacAdam, 1942). The values were calculated in u'v' CIE 1976 units and multiplied by 106. All of the means corresponding to color discrimination thresholds at different locations in the color space for all alcoholic groups were within the tolerance limits of the statistical norms of the age-matched control groups, with the exception of Ellipses 1 and 4 for the oldest age group. Values for individual alcoholic subjects are shown in Table 2.

\section{Comparison with previous studies}

Acquired color vision losses have frequently been observed among chronic alcoholics (Cruz-Coke \& Varela, 1965; Reynolds, 1979; Mergler et al., 1988; Braun \& Richer, 1993; Kapitany et al., 1993; Shimozono, Townsend, Ilsen, \& Bright, 1998). All of these studies used the Ishihara pseudoisochromatic test or color arrangement tests to evaluate color vision performance. Moreover, blue-yellow visual field perimetry has revealed color vision deficiencies in chronic alcoholic subjects (de Carvalho Júnior, Danda, Dantas, Arraes, \& Cavalcanti, 2006). The Ishihara test is well suited to detect red-green congenital color vision deficiencies but is not entirely appropriate for other forms of color vision dysfunctions, such as acquired red-green or blue-yellow color vision losses. The Ishihara test also does not provide the quantitative assessment of color vision deficiencies which other color arrangement tests and color discrimination threshold measurements may provide.

Color arrangement tests differ in several ways from the Mollon-Reffin procedure that was used in the present study to measure color discrimination thresholds. Color arrangement tests, such as the Farnsworth-Munsell and Lanthony tests, are generally designed to measure the ability to distinguish different hues having the same saturation and luminance, whereas the MollonReffin test evaluates chromaticity thresholds (i.e., simultaneous differences in hue and saturation at the same luminance level). Color arrangement tests are performed to allow a wide range of freedom such that the subject is free to manipulate the hues until satisfied with the arrangement. The Mollon-Reffin test follows the strict, previously determined staircase procedure and response times which limit the subject's degree of freedom. However, the Mollon-Reffin test displays the target amid luminance and spatial noise to mimic the complex natural environment, whereas color arrangement tests are typically performed under simpler laboratory conditions. Finally, in psychophysical terms, measurements of color discrimination threshold, such as those performed with the Mollon-Reffin test, and measurements of the subject's ability to distinguish colors, such as those performed with the FarnsworthMunsell and Lanthony color arrangement tests, assess different dimensions of sensory-motor performance.

Given the limitations of the Ishihara test and the differences between the results provided by color arrangement tests and the Mollon-Reffin test, the present study provides valuable qualitative and quantitative data that characterize the color vision deficiency associated with chronic alcoholism.

\section{Pathophysiology of color vision loss in chronic alcoholism}

Retinoscopy has provided evidence for ganglion cell degeneration as a possible pathophysiological mechanism to explain the visual dysfunction symptoms observed in several metabolic neuropathies, such as 
heredodegenerative diseases (e.g., Leber's hereditary optic neuropathy), nutritional deficiencies (e.g., vitamin B9 [folic acid] and vitamin B12 [cobalamin] deficiencies), and toxic conditions (e.g., those associated with exposure to ethambutol, cyanide, ethanol, and tobacco, among many other toxicants; Plant \& Perry, 1990; Sadun et al., 1994; de Lima et al., 2006; Orssaud, Roche, \& Dufier, 2007). Impairment of mitochondrial function attributable to genetic mutations, endogenous toxicity secondary to vitamin deficiency, or toxic exposure to exogenous agents has been considered a common pathway leading to neuronal degeneration in these diseases (Sadum, 2002a, b; Carelli, Ross-Cisneros, \& Sadun, 2004; Sadun \& Carelli, 2006; Orssau et al., 2007).

Detailed longitudinal studies of color vision and other visual functions in subjects with a clinical history of chronic alcoholism are still sparse and will be important to better understand the possible relationships between ethanol abuse and other toxicological and malnourishment conditions. A limited number of studies have demonstrated that some of the visual deficits associated with alcoholism, malnourishment, or toxicity by other agents might be reversible, especially if the causative agent is removed (Orssaud et al., 2007). A quantitative assessment of contrast sensitivity (spatial and temporal, chromatic and achromatic) and color discrimination, which are fundamental properties of human vision, are the next logical steps in the research on vision and chronic alcoholism.

\section{Acknowledgements}

Supported by the FINEP IBN-Net \#01.06.084200, CNPq-PRONEX/FAPESPA \#2268, CNPq \#486351/2006-8, CNPq \#476744/2009-1, CNPq \#620248/2006-8, CNPq \#620037/2008-3, and CAPESPROCAD\#182/2007.AJOC and MITC received CAPES fellowships for graduate students. ARR received a CNPq graduate student fellowship, a CAPES graduate student fellowship, and a CNPq postdoctoral fellowship. LCLS is a CNPq research fellow. The authors are thankful to Rogerio Carvalho and Bruno Duarte Gomes.

\section{References}

Ambrose, M.L., Bowden, S.C., \& Whelan, G. (2001). Thiamin treatment and working memory function of alcohol-dependent people: preliminary findings. Alcoholism: Clinical and Experimental Research, 25, 112-116.

Andre, J.T., Tyrrell, R.A., Leibowitz, H.W., Nicholson, M.E., \& Wang, M. (1994). Measuring and predicting the effects of alcohol consumption on contrast sensitivity for stationary and moving gratings. Perception and Psychophysics, 56, 261-267.

Arden, G.B. (1978). The importance of measuring contrast sensitivity in cases of visual disturbance. British Journal of Ophthalmology, 62, 198-209.

Braun, C.M., \& Richer, M. (1993). A comparison of functional indexes, derived from screening tests, of chronic alcoholic neurotoxicity in the cerebral cortex, retina and peripheral nervous system. Journal of Studies on Alcohol, 54, 11-16.
Brecher, G.A., Hartman, A.P., \& Leonard, D.D. (1955). Effect of alcohol on binocular vision. American Journal Ophthalmology, 39, 44-52.

Campbell, F.W., \& Green, D.G. (1965). Optical and retinal factors affecting visual resolution. Journal of Physiology, 181, 576-593.

Campbell, F.W., \& Robson, J.G. (1968). Application of Fourier analysis to the visibility of gratings. Journal of Physiology, 197, 551-566.

Carelli, V., Ross-Cisneros, F.N., \& Sadun, A.A. (2004). Mitochondrial dysfunction as a cause of optic neuropathies. Progress in Retinal and Eye Research, 23, 53-89.

Cornsweet, T.N. (1962). The staircase-method in psychophysics. American Journal of Psychology, 75, 485-491.

Cruz-Coke, R., \& Varela, A. (1965). Colour-blindness and alcohol addiction. Lancet, 2, 1348.

de Carvalho Júnior, J.F., Danda, D., Dantas, H., Arraes, T.A., \& Cavalcanti, E. (2006). Perimetria azul-amarelo em usuários de tabaco-álcool. Arquivos Brasileiros de Oftalmologia, 69, 675-678.

de Lima, R.C.R., Carvalho, F., Campos, S.B.S., \& Dantas, H. (2006). Análise da camada de fibras nervosas da retina em usuários crônicos do tabaco e álcool. Arquivos Brasileiros de Oftalmologia, 69, 323-325.

Diamond, I., \& Messing R. O. (1994). Neurologic effects of alcoholism. Western Journal of Medicine, 161, 279-287.

Dixon, W.J., \& Massey, F.J. (1969). Introduction to statistical analysis. New York: McGraw-Hill.

Glanz, J., Grant, B., Monteiro, M., \& Tabakoff, B. (2002) WHO/ISBRA study on state and trait markers of alcohol use and dependence: analysis of demographic, behavioral, physiologic, and drinking variables that contribute to dependence and seeking treatment. Alcoholism: Clinical and Experimental Research, 26, 1047-1061.

Handler, C.E.,\& Perkin, G.D.(1983).Wernicke's encephalopathy. Journal of the Royal Society of Medicine, 76, 339-341.

Hill, J.C., \& Toffolon, G. (1990). Effect of alcohol on sensory and sensorimotor visual functions. Journal of Studies on Alcohol, 51, 108-113.

Kapitany, T., Dietzel, M., Grünberger, J., Frey, R., Koppensteiner, L., Schleifer, G., \& Marx, B. (1993). Color vision deficiencies in the course of acute alcohol withdrawal. Biological Psychiatry, 33, 415-422.

Laranjeira, R., Pinsky, I., Sanches, M., Zaleski, M., \& Caetano, R. (2009). Alcohol use patterns among brazilian adults. Revista Brasileira de Psquiatria, 13, 1-10.

Lieber, C.S. (1980). Alcohol, protein metabolism, and liver injury. Gastroenterology, 79, 373-390.

Lieber, C.S. (1997). Ethanol metabolism, cirrhosis and alcoholism. Clinica Chimica Acta, 257, 59-84.

Li, T., Yin, S., Crabb, D.W., O’Connor, S., \& Ramchandani, V.A. (2001). Genetic and environmental influences on alcohol metabolism in humans. Alcoholism: Clinical and Experimental Research, 25, 136-144.

Lorimier, A.A. (2000). Alcohol, wine, and health. American Journal of Surgery, 180, 357-361.

MacAdam, D.L. (1942). Visual sensitivities to color differences in daylight. Journal of the Optical Society of America, 32, 247-274.

Mailliard, W.S. \& Diamond, I. (2004). Recent advances in the neurobiology of alcoholism: the role of adenosine. Pharmacology \& Therapeutics,101, 39-46.

Marlatt, G.A., \& Witkiewitz, K. (2002). Harm reduction approaches to alcohol use: health promotion, prevention, and treatment. Addictive Behaviors, 27, 867-886.

Merck Manual of Diagnosis and Therapy (2008). Toxic amblyopia. http://www.merck.com/mmpe/sec09/ch107/ch107f.html - sec09ch107-ch107e-703. Accessed February 6, 2010.

Mergler, D., Blain, L., Lemaire, J., \& Lalande, F. (1988). Colour vision impairment and alcohol consumption. Neurotoxicology and Teratology, 10, 255-260.

Merigan, W., Freeman, A., \& Meyers, S.P. (1997). Parallel processing streams in human visual cortex. Neuroreport, 8, 3985-3991.

Miller, R.J. (1991). The effect of ingested alcohol on fusion latency at various viewing distances. Perception Psychophysics, 50, 575-583.

Mollon, J.D., \& Reffin, J.P. (1989). A computer-controlled colour vision test that combines the principles of Chibret and of Stilling. Journal of Physiology, 414, 5P.

Murata, T., Fujito, T., Kimura, H., Omori, M., Itoh, H., \& Wada, Y. (2001). Serial MRI and ${ }^{1} \mathrm{H}$-MRS of Wernicke's encephalopathy: report of a case with remarkable cerebellar lesions on MRI. Psychiatry Research, 108, 49-55.

Newman, H., \& Fletcher, E. (1941). The effect of alcohol on vision. American Journal of the Medical Sciences, 202, 723-731.

Orssaud, C., Roche, O., \& Dufier, J.L. (2007). Nutritional optic 
neuropathies. Journal of the Neurological Sciences, 262, 158-164.

Plant, G.T., \& Perry, V.H. (1990). The anatomical basis of the caecocentral scotoma: new observations and a review. Brain, 113, 1441-1457.

Preedy, V.R., Reilly, M.E., Patel, V.B., Richardson, P.J., \& Peters, T.J. (1999). Protein metabolism in alcoholism: effects on specific tissues and the whole body. Nutrition, 15, 604-608.

Regan, B.C., Reffin, J.P., \& Mollon, J.D. (1994). Luminance noise and the rapid determination of discrimination ellipses on colour deficiency. Vision Research, 34, 1279-1299.

Rehm, J., \& Gmel, G. (2003). Alcohol consumption and total mortality/ morbidity: definitions and methodological implications. Best Practice and Research Clinical Gastroenterology, 17, 497-505.

Reynolds, D.C. (1979). A visual profile of the alcoholic driver. American Journal of Optometry and Physiological Optics, 56, 241-251.

Riley, L., \& Marshall, M. (1999). Alcohol and public health in 8 developing countries (pp. 1-186). Geneva: World Health Organization.

Rodrigues, A.R., Botelho de Souza, C.R., Braga, A.M., Rodrigues, P.S.S., Silveira, A.T., Damin, E.T.B., Côrtes, M.I.T., Castro, A.J.O., Mello, G.A., Vieira, J.L.F., Pinheiro, M.C.N., Ventura, D.F., \& Silveira, L.C.L. (2007). Mercury toxicity in the Amazon: contrast sensitivity and color discrimination of subjects exposed to mercury. Brazilian Journal of Medical and Biological Research, 40, 415-424.

Room, R., Babor, T., \& Rehm, J. (2005). Alcohol and public health. Lancet, 365, 519-530.

Rudolf, H., \& Priebe, S. (2002). Subjective quality of life and depressive symptoms in women with alcoholism during detoxification treatment. Drug and Alcohol Dependence, 66, 71-76.

Sadun, A.A. (2002a). Mitochondrial optic neuropathies. Journal of Neurology, Neurosurgery and Psychiatry, 72, 423-425.

Sadun, A.A. (2002b). Metabolic optic neuropathies. Seminars in Ophthalmology, 17, 29-32.

Sadun, A.A., \& Carelli, V. (2006). The role of mitochondria in health, ageing, and diseases affecting vision: control of mitochondrial mediated apoptosis will become a holy grail. British Journal of Ophthalmology, 90, 809-810.

Sadun, A.A., Martone, J.F., Muci-Mendoza, R., Reyes, L., DuBois, L., Silva, J.C., Roman, G., \& Caballero, B. (1994). Epidemic optic neuropathy in Cuba: eye findings. Archives of Ophthalmology, 112, 691-699.

Salomão, S.R., \& Ventura, D.F. (1995). Large sample population age norms for visual acuities obtained with Vistech-Teller Acuity Cards. Investigative Ophthalmology and Visual Science, 36, 657-670.

Santolaria, F., González-Reimers, E., Perez-Manzano, J.L., Milena, A., Gómez-Rodríguez, M.A., González-Díaz, A., Vega, M.J., \& Martínez-Riera, A. (2000). Osteopenia assessed by body composition analysis is related to malnutrition in alcoholic patients.
Alcohol, 22, 147-157.

Schuckit, M.A. (2009). Alcohol-use disorders. Lancet, 373, 492-501.

Schorling, J.B., \& Buchsbaum, D.G. (1997). Screening for alcohol and drug abuse. Medical Clinics of North America, 81, 845-865.

Serafini, M., Maiani, G., \& Ferro-Luzzi, A. (1998). Alcohol-free red wine enhances plasma antioxidant capacity in humans. Journal of Nutrition, 128, 1003-1007.

Shimozono, M., Townsend, J.C., Ilsen, P.F., \& Bright, D.C. (1998). Acute vision loss resulting from complications of ethanol abuse. Journal of the American Optometric Association, 69, 293-303.

Silveira, L.C.L., Damin, E.T.B., Pinheiro, M.C.N., Rodrigues, A.R., Moura, A.L.A., Côrtes, M.I.T., \& Mello, G.A. (2003). Visual dysfunction following mercury exposure by breathing mercury vapour or by eating mercury-contaminated food. In J.D. Mollon, I. Pokorny \& K. Knoblauch K (Eds.), Normal and defective colour vision (pp. 407-417). Oxford: Oxford University Press.

Silveira, L.C.L., Saito, C.A., Lee, B.B., Kremers, J., da Silva Filho, M., Kilavik, B.E., Yamada, E.S., \& Perry, V.H. (2004) Morphology and physiology of primate M- and P-cells. Progress in Brain Research, 144, 21-46.

Silveira, L.C.L., Saito, C.A., de Mello Júnior, H.D., Silveira, V.A., Souza, G.S., Rodrigues, A.R., \& da Silva Filho, M. (2008) Division of labour between the $\mathrm{M}$ and $\mathrm{P}$ visual pathways: different visual pathways minimize joint entropy differently. Psychology and Neuroscience, 1, 3-14.

Smith, J.W. (1972). Color vision in alcoholics. Annals of the New York Academy of Sciences, 197, 143-147.

Torvik, A., \& Torp, S. (1986). The prevalence of alcoholic cerebellar atrophy: a morphometric and histological study of an autopsy material. Journal of the Neurological Sciences, 75, 43-51.

Ventura, D.F., Silveira, L.C.L., Rodrigues, A.R., Nishi, M., de Souza, J.M., Gualtieri, M., Bonci, D.M.O., Nunes, A.P., \& Costa, M.F. (2003). Preliminary norms for the Cambridge colour test. In J.D. Mollon, I. Pokorny \& K. Knoblauch K (Eds.), Normal and defective colour vision (pp. 331-339). Oxford: Oxford University Press.

Wang, M.Q., Taylor-Nicholson, M.E., Airhihenbuwa, C.O., Mahoney, B.S., Fitzhugh, E.C., \& Christina, R. (1992). Psychomotor and visual performance under the time-course effect of alcohol. Perceptual and Motor Skills, 75, 1095-1106.

Westheimer, G. (1960). Modulation thresholds for sinusoidal light distributions on the retina. Journal of Physiology, 152, 67-74.

World Health Organization (2010). Alcohol. http://www.who.int/substance abuse/facts/alcohol/en/index.html. Accessed February 6, 2010.

Zafar, A., \& Sergott, R.C. (2008). Toxic / nutritional optic neuropathy. http:// www.emedicine.com/oph/topic750.htm. Accessed February 6, 2010. 